\title{
ST segment depression in hypertensive patients: A comparison of exercise test versus Holter ECG
}

\author{
Sakir Uen' \\ Rolf Fimmers ${ }^{2}$ \\ Burkhard Weisser ${ }^{3}$ \\ Osman Balta' \\ Georg Nickenig' \\ Thomas Mengden' \\ 'Division of Hypertension \\ and Vascular Medicine, Department \\ of Internal Medicine II, University \\ Clinic, Bonn, Germany; ${ }^{2}$ Department \\ of Biometry and Medical Statistics, \\ University of Bonn, Bonn, Germany; \\ ${ }^{3}$ Department of Sports Medicine, \\ University of Kiel, Kiel, Germany
}

\begin{abstract}
Introduction: This study compared ST segment depression (ST depression) during cycle ergometry (ergometry) versus simultaneous 24-hour ambulatory blood pressure measurement and electrocardiogram recording (24-h ABPM/ECG) during everyday life.

Methods: In a German multicenter study, ergometry and 24-h ABPM/ECG records of 239 hypertensive patients were retrospectively analyzed. ST depression was defined as an ST segment depression (1 mm limb or chest recordings V1 to V6) in an incremental cycle ergometry, or $1 \mathrm{~mm}$ in the 24-h ABPM/ECG recording under everyday conditions. Blood pressure parameters at the onset of ST depression in the context of the respective method were compared.

Results: 18 patients had ST depression only in ergometry (group B), 23 had ST depression only during 24-h ABPM/ECG monitoring (group C) and 28 patients had ST depression with both methods (group D). Group A had no ST depression with any method. In group D, at the onset of ST depression with 24-h ABPM/ECG investigation, all parameters except diastolic blood pressure were significantly lower compared with the corresponding parameters at the onset of ST depression with ergometry (systolic blood pressure: $148 \pm 19$ vers $188 \pm 35 \mathrm{mmHg}$, $\mathrm{p}<0.001$; heart rate: $93 \pm 12$ vs $120 \pm 21$ beat $/ \mathrm{min}, \mathrm{p}<0.0001$; double product: $13,714 \pm 2315$ vs $22,992 \pm 3,985 \mathrm{mmHg} / \mathrm{min}), \mathrm{p}<0.0001)$.

Conclusion: ST depressions during everyday life detected by 24-h ABPM/ECG are characterized by a substantially lower triggering threshold for blood pressure level parameters compared with ergometry. The two methods detecting ischemia do not replace but complement each other.
\end{abstract}

Keywords: ST segment depression, arterial hypertension, blood pressure measurement, combined 24-h ABPM/ECG

\section{Introduction}

Several study groups have reported an unfavorable prognosis for patients with ST segment depression (ST depression) relating in particular to the development of adverse cardiovascular events such as sudden cardiac death, survivable myocardial infarction, and the manifestation of unstable angina (Tzivoni et al 1988; Fleg et al 1990; Pepine et al 1997; Aronow et al 2002). ST depression can be detected under exercise conditions or during daily life, for example by means of ST segment analysis (Hedblad and Janzon 1992; Benhorin et al 1993; Sajadieh et al 2005). Since the 1990s, several investigators have attempted to establish whether ST depression detected by means of ergometry or by 24-hour electrocardiogram (ECG) monitoring have the same ischemic threshold (Banai et al 1990; Benhorin et al 1993a, 1993b). These studies showed a significantly lower increase in heart rate at the time of ST depression in the 24-h ECG, than in ergometry (Benhorin et al 1991; Raby et al 1993; Gaetano et al 1997). The blood pressure parameters and thus also the product of systolic blood pressure and heart rate (double product, DP) could not be compared in these studies for methodological reasons: the technical prerequisites for simultaneous ambulant blood pressure measurement during the ST depression in the 24-h ECG were not available. 
Therefore this study compares the ischemic threshold in the level of blood pressure parameters at the onset of ST depression in ergometry, and in combined 24-h ambulatory blood pressure measurement (ABPM)/ECG investigation, in patients with hypertension.

\section{Methods}

In a retrospective multicenter German study, 12 centers for cardiovascular disease supplied both 24-h ABPM/ECG and cycle ergometric recordings from 286 patients with arterial hypertension to the University of Bonn for evaluation of ST depression. The inclusion criterion was treated or untreated arterial hypertension. The University's ethical committee approved the study. The following exclusion criteria applied: valve disease, pericarditis, cardiomyopathies, heart block pattern on the resting ECG, abnormal serum electrolyte levels, pre-excitation syndromes, digitalis administration, atrial fibrillation, frequent ventricular extrasystoles or pacemaker ECG, angina pectoris without alteration in the ST segment in ergometry, and high-artifact ECG registrations, baseline ST depression $\leq-0.05 \mathrm{mV}$ in resting ECG.

The 24-h ABPM/ECG (CardioTens, Meditech, Hungary) unit used in this study by all centers is an ST-triggered, 24-h ABPM/ECG device, capable of performing continuous ST segment analysis, storing ECG tracings, and obtaining ambulatory blood pressure readings. The blood pressure measuring unit was validated according to the BHS (British Hypertension Society) protocol (Barna et al 1998). Blood pressure readings were automatically recorded by the oscillometric method, every 15 minutes between 10.00 a.m. and 10.00 p.m., every 30 minutes between 10.00 p.m. and 06.00 a.m., and every 10 minutes between 06.00 a.m. and 10.00 a.m. The ECG unit of the device routinely recorded a 30second ECG tracing with two leads (CM5 and CC5) via two independent channels every 5 minutes. In case of a horizontal or descending ST depression (1 mm-1 minute duration at a 1 minute interval from the preceding episode), an ECG tracing lasting 60 seconds was recorded and an additional blood pressure measurement was automatically initiated by the trigger mechanism of the device (Figure 1).

Before the start of the 24-h investigation, the isoelectric reference point (PQ segment), J point, L point ( $80 \mathrm{~ms}$ after the J point), and an ST-segment detection interval of at least $3 \mathrm{~mm}$ as the initial ST level, were calculated individually for each patient. Where applicable, the investigator had the option of manually correcting the initial ST parameter calculated by the device. An initial ST level of $\geq 0 \mathrm{mV}$ required an ST depression episode to be at least -0.10 ; an initial ST level of $<0 \mathrm{mV}$ required the $\mathrm{ST}$ segment to be depressed by a further -0.10 in relation to the initial ST, to be counted as an episode of ST segment depression. If the ST segment analysis showed a $24-\mathrm{h}$ mean of $\leq-0.10 \mathrm{mV}$, the patient was excluded from the statistical analysis. Independently of each other, two experts checked the ECG recordings and excluded artifactual ST segment depression.

The cycle ergometry was conducted in accordance with the standard protocol of the World Health Organization. The initial power output was 25 or $50 \mathrm{~W}$, followed by increases of $25 \mathrm{~W}$ every 2 minutes. ST depression was defined as 1 mm ST segment depression (limb or chest wall recordings V1 to V6) in an incremental cycle ergometry.

Patients with no ST depression in any method (group A), with ST depression only in ergometry (group B), with ST depression only during 24-h ABPM/ECG monitoring (group C), with ST depression in both methods (group D) were compared. Blood pressure parameters at the onset of ST depression in the context of the respective method were compared.

The DP at the time of an ST depression during ergometry was compared as the primary end point with the corresponding DP of the 24-h measurement. Other parameters investigated were anthropometric data (age, gender, height, weight, BMI), cardiovascular risk factors and disease, intake of antihypertensive drugs and intake of co-medication, Sokolow-Index (Sv1 + Rv5/6)mV, data of the 24-h ABPM/ ECG measurement (mean value in excess of 24 hour, respective systolic and diastolic pressure, blood pressure amplitude, mean arterial pressure, heart rate, mean and maximum DP, and corresponding parameter at the beginning of an episode of ST depression, magnitude of ST-segment depression $(\mathrm{mV})$, percentage of patients with controlled hypertension (24-h mean systolic/diastolic value $<130 / 80 \mathrm{mmHg}$ ) as well as ergometric data (maximum exercise, resting heart rate and maximum heart rate, metabolic equivalent, resting blood pressure and maximum pressure, resting DP and maximum DP and the corresponding parameters at the time of ST depression, magnitude of ST-segment depression (mV)).

The statistical method used compared mean values \pm standard deviations, by Student's t-test. For each variable in question a global test was performed to compare the values between the four groups. This was an ANOVA for the quantitative values and an exact Fisher-test applied to the $2 \times 4$ Table for the qualitative values. In case of a $p$ below 0.05 , Tukey's test was used to perform multiple comparisons between the four groups, to calculate the quantitative values. In case of a p below 0.05 for the qualitative values 
(1a)

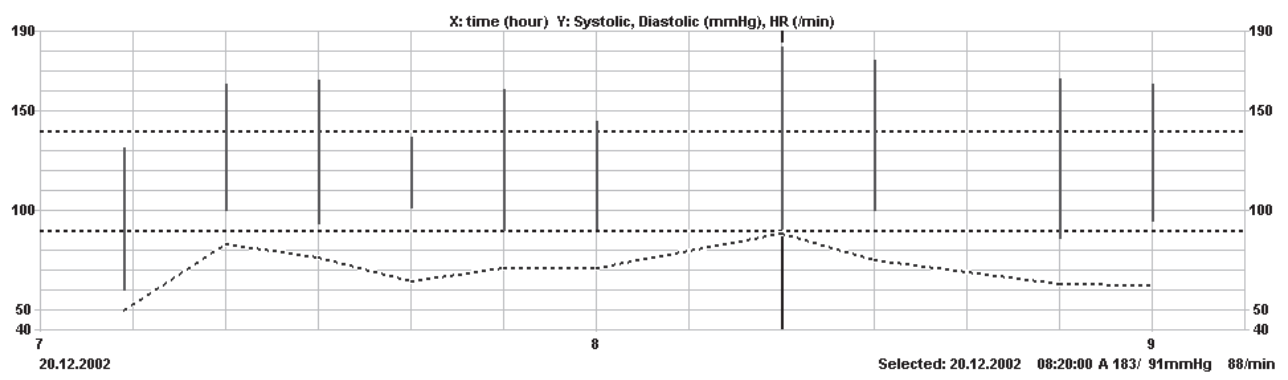

(1b)

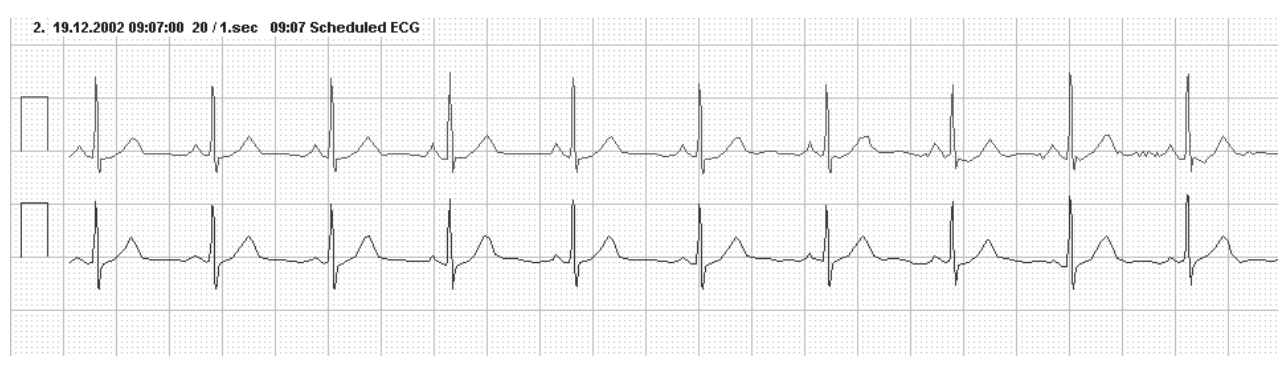

(1c)

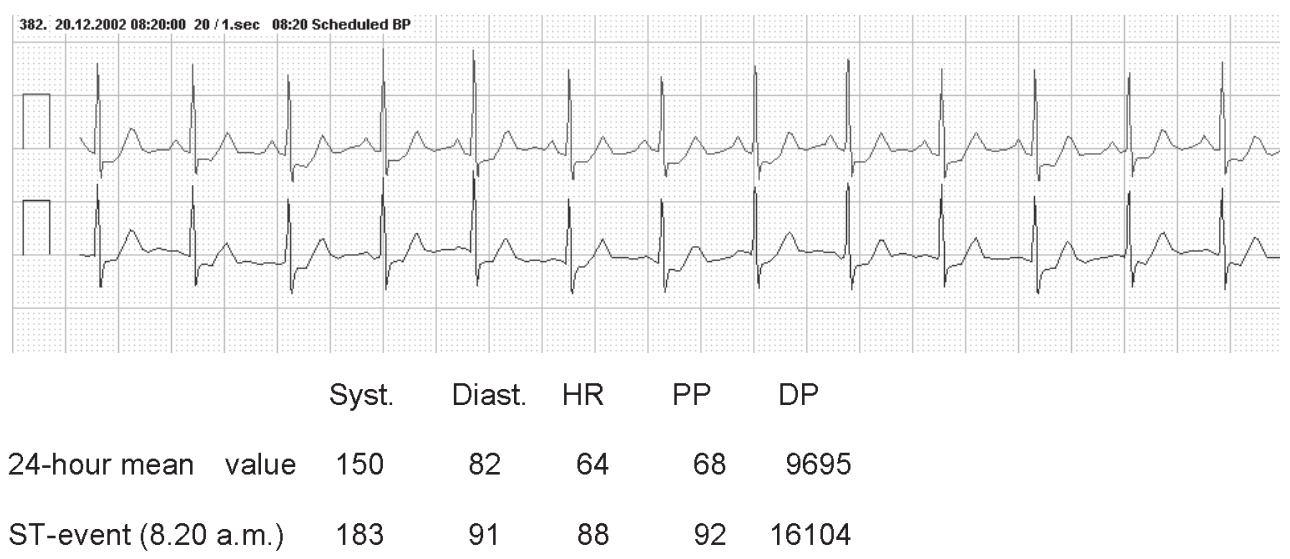

Figure I An excerpt from the 24-hour daily profile of a patient with poorly controlled isolated systolic arterial hypertension (the black bars show the systolic and diastolic blood pressure values and the cross-hatched curve shows the heart rate) (a). Electrocardiogram (ECG) lines with two independent bipolar leads at the beginning of the CardioTens monitoring (b). The ECG unit registered an ST depression episode at 8.20 a.m. that complied with the I-I-I rule (c). This triggered an additional blood pressure measurement by the 24-h ambulatory blood pressure measuring unit of the device (marked with a bar in a). The systolic (syst.), diastolic (diast.) blood pressure, pulse pressure (PP) mmHg, heart rate (HR) I/minute, and double product (DP) $\mathrm{mmHg} /$ minute in the ST event are compared with the 24-h means table.

in the global test, the multiple group comparisons were corrected by a permutation approach (SAS Proc Multtest). The descriptive approach of this analysis meant that a correction for the multiplicity of testing across the variables was not performed.

\section{Results}

Both the ergometric and 24-h ABPM/ECG recordings of 286 patients were available. After considering the exclusion criteria (47 patients were excluded), the statistical analysis was based on the remaining 239 patients with both recordings. As detected by at least one of the two methods, 69 patients had an ST depression. Altogether, 51 patients had an ST depression in the 24-h ABPM/ECG investigation, whereas only 46 patients showed ST depression in cycle ergometry, although this was conducted with the objective of maximum stress.

Patient characteristics are compared in Table 1. The Sokolow index was most pronounced in groups D and C, where it was significantly higher than in group A $(\mathrm{p}<0.05)$. No significant difference could be observed between the 
Table I Patient characteristics and percentage relative frequency of parameters

\begin{tabular}{|c|c|c|c|c|}
\hline & $A(n=170)$ & $B(n=18)$ & $C(n=23)$ & $D(n=28)$ \\
\hline Sex m: male, f: female & $\mathrm{m}: \mathrm{I} / 2 \mathrm{f:58}$ & $m: 12$ f:6 & $m: 11 \mathrm{f}: 12$ & $m: 17 \mathrm{f}: 1 \mathrm{I}$ \\
\hline Age (y) & $56 \pm 13$ & $56 \pm 7$ & $62 \pm 10$ & $59 \pm 11$ \\
\hline Height $(\mathrm{cm})$ & $172 \pm 9$ & $172 \pm 8$ & $169 \pm 8$ & $17 \mid \pm 8$ \\
\hline Weight (kg) & $86 \pm 17$ & $78 \pm 12$ & $83 \pm 15$ & $79 \pm 14$ \\
\hline Body Mass Index & $29.1 \pm 5.4$ & $26.4 \pm 4.6$ & $29.2 \pm 4.4$ & $27.1 \pm 3.6$ \\
\hline Total cholesterol $(\mathrm{mg} / \mathrm{dl})$ & $211 \pm 40$ & $192 \pm 41$ & $220 \pm 50$ & $208 \pm 52$ \\
\hline \multirow[t]{2}{*}{ Sokolow index $(\mathrm{mV})$} & $2.0 \pm 0.7$ & $2.3 \pm 0.6$ & $2.5 \pm 0.9^{a}$ & $2.7 \pm 0.6^{a}$ \\
\hline & $\%$ & $\%$ & $\%$ & $\%$ \\
\hline 24-h ABPM < $<30 / 80 \mathrm{~mm} \mathrm{Hg}$ & 67 & 56 & 43 & 43 \\
\hline Diabetes mellitus & 20 & 18 & 17 & 11 \\
\hline Dyslipoproteinemia & 72 & 71 & 48 & 64 \\
\hline Smokers & 25 & 6 & 30 & 29 \\
\hline Myocardial infarction & 14 & 24 & 14 & 18 \\
\hline Coronary heart disease & 33 & 47 & 54 & 43 \\
\hline Revascularization & 27 & 35 & 32 & 29 \\
\hline \multicolumn{5}{|c|}{ Antihypertensive drugs and co-medication } \\
\hline Beta-blocker & 58 & 59 & 61 & 39 \\
\hline Diuretics & 39 & 29 & 52 & 43 \\
\hline Calcium-channel antagonists & 17 & 6 & 26 & 32 \\
\hline ACE inhibitors & 50 & 35 & 30 & 35 \\
\hline ATI antagonists & 15 & 29 & 30 & II \\
\hline Antiplatelet drugs & 41 & 47 & 57 & 57 \\
\hline Nitrate & 12 & 24 & 17 & 14 \\
\hline Lipid-lowering agents & 40 & 59 & 26 & 29 \\
\hline
\end{tabular}

Notes: Patients with ST depression in neither method (group A), with ST depression in the exercise test alone (group B), with ST depression in 24-h ABPM/ECG monitoring alone (group C), and with ST depression in both methods (group D). a:ANOVA-test $p<0.05$ of the group compared with group A (Tukey's test for the multiple comparison among the four groups was not significant).

four groups in these parameters: intake of antihypertensive agents (beta blockers, diuretics, calcium channel blockers, ACE inhibitors, AT-1 receptor blockers) aspirin or nitrates and diagnosis of diabetes mellitus. Twenty-one percent of patients were not treated for antihypertension. The ST depression in $30 \%$ of treated patients was not significantly different to that in untreated patients $(32 \%)$. Smoking tended not to be significantly higher in groups B and $\mathrm{C}$ than in the other groups. The rates for cardiovascular disease did not differ significantly among the four groups. The percentage of patients with controlled blood pressure (24-h ABPM $<130 / 80 \mathrm{mmHg}$ ) was lower in groups $\mathrm{C}$ and $\mathrm{D}$ compared with group A.

Table 2 shows the 24-h ABPM/ECG mean values, the parameters of the exercise test.

Resting blood pressure parameters measured immediately before ergometry did not differ significantly among the four groups. During ergometry, group B did not attain a significantly higher maximum exercise level than groups
A, C, and D. The calculation of physical exercise tolerance by means of metabolic equivalent (MET) tended to be higher in group B than in groups A, C, and D. Accordingly, the product of blood pressure and heart rate (double product) in group B was highest at the time of maximum exercise, but was not significant compared with groups A, C, and D.

An ST depression in ergometry was observed in groups $\mathrm{B}$ and $\mathrm{D}$. The parameters measured in ergometry at the time of ST depression tended to be higher in group B than in group D. ST depression in the 24-h ABPM/ECG investigation was observed in groups $\mathrm{C}$ and $\mathrm{D}$. The hemodynamic parameters measured at the time of ST depression in the 24-h ABPM/ECG investigation were the same in the two groups (Tables 3 and 4 ).

Systolic and diastolic blood pressure, heart rate, and the double product at the time of ST segment depression in ergometry and 24-h ABPM/ECG investigation were compared. Patients of group D had both, ST depression in ergometry and in the 24-h ABPM/ECG investigation. At the 
Table 2 Hemodynamic parameters of ergometry and 24-h ABPM

\begin{tabular}{|c|c|c|c|c|}
\hline Resting blood pressure values & Group A & Group B & Group C & Group D \\
\hline Systolic BP (mmHg) & $132 \pm 20$ & $138 \pm 14$ & $137 \pm 17$ & $137 \pm 20$ \\
\hline Diastolic BP (mmHg) & $84 \pm 12$ & $91 \pm 12$ & $87 \pm 15$ & $82 \pm 11$ \\
\hline Heart rate $(\mathrm{I} / \mathrm{min})$ & $76 \pm 14$ & $71 \pm 14$ & $73 \pm 15$ & $73 \pm 13$ \\
\hline Double product (mmHg/min) & $10131 \pm 2286$ & $9869 \pm 2604$ & $10113 \pm 2247$ & $9920 \pm 2174$ \\
\hline \multicolumn{5}{|l|}{ Peak exercise values } \\
\hline Maximum exercise $(\mathrm{W})$ & $|28 \pm 5|$ & $160 \pm 46$ & $124 \pm 49$ & $130 \pm 45$ \\
\hline MET (metabolic equivalent) & $6.1 \pm 1.7$ & $7.3 \pm 1.7$ & $5.9 \pm 1.6$ & $6.2 \pm 1.7$ \\
\hline Systolic BP (mmHg) & $191 \pm 37$ & $197 \pm 27$ & $192 \pm 34$ & $203 \pm 39$ \\
\hline Diastolic BP (mmHg) & $90 \pm 16$ & $97 \pm 11$ & $89 \pm 16$ & $90 \pm 17$ \\
\hline Heart rate $(1 / \mathrm{min})$ & $128 \pm 24$ & $138 \pm 17$ & $121 \pm 16$ & $132 \pm 23$ \\
\hline Double product (mmHg/min) & $2478 I \pm 7554$ & $27077 \pm 5063$ & $23357 \pm 5967$ & $26840 \pm 7490$ \\
\hline \multicolumn{5}{|l|}{ 24-h blood pressure mean values } \\
\hline Systolic BP (mmHg) & $126 \pm 14$ & $126 \pm 11$ & $136 \pm 17^{a}$ & $|3| \pm 14$ \\
\hline Diastolic BP (mmHg) & $75 \pm 9$ & $77 \pm 7$ & $76 \pm 10$ & $75 \pm 7$ \\
\hline Heart rate $(\mathrm{I} / \mathrm{min})$ & $74 \pm 11$ & $67 \pm 8$ & $73 \pm 11$ & $73 \pm 9$ \\
\hline Pulse pressure $(\mathrm{mmHg})$ & $51 \pm 9$ & $49 \pm 7$ & $60 \pm 15^{a, b}$ & $55 \pm 13$ \\
\hline Mean arterial pressure $(\mathrm{mmHg})$ & $92 \pm 10$ & $93 \pm 8$ & $97 \pm 12$ & $94 \pm 8$ \\
\hline Double product $(\mathrm{mmHg} / \mathrm{min})$ & $9279 \pm 1753$ & $8459 \pm 1266$ & $9822 \pm 1708$ & $9537 \pm 1283$ \\
\hline Double product peak & $16848 \pm 4268$ & $17982 \pm 3135$ & $17215 \pm 4638$ & $16769 \pm 2566$ \\
\hline
\end{tabular}

time of ST depression in the 24-h ABPM/ECG investigation, all parameters except diastolic blood pressure were significantly lower compared with the corresponding parameters at the time of ST depression in ergometry (Table 3). In Group D the magnitude of ST depression was not significantly different in 24-h ABPM/ECG as compared to ergometry ( $-0.16 \pm$ 0.04 versus $-0.15 \pm 0.04 \mathrm{mV}$ ). Patients with ST depression in ergometry only, were compared with patients with ST depression found only in the 24-h ABPM/ECG investigation (ie, group B compared with group C), and the same difference was also observed (Table 4).

\section{Discussion}

Because patients with ST depression have a poor cardiovascular prognosis, determining the exercise level at which such depression occurs is important. The product of systolic blood pressure and heart rate is usually designated in the literature as a "double product". It is closely correlated with myocardial oxygen consumption. Of the hemodynamic parameters which can be measured simply and noninvasively, DP defines cardiac load and thus oxygen consumption better than either blood pressure or heart rate alone. In the present investigation, DP was determined at the time of ST depression during cycle ergometry and over 24 hours in everyday life. In the comparison of the two methods (24-h $\mathrm{ABPM} / \mathrm{ECG}$ monitoring and ergometry), it is striking that the maximum DP in ergometry was very much higher than the DP determined during the $24-h$ measurement. This initially indicates that ergometry was conducted under maximum exercise and is the more noteworthy, becasuse ST depression nevertheless occurred in more patients during the $24-\mathrm{h}$ measurement.

The core result of the present study is that ST depression occurred only in standardized incremental ergometry at very much higher exercise levels (or at a higher DP) than in everyday life. These results might be helpful in understanding the pathophysiological role of hemodynamic parameters in patients with hypertension or ST depression in ergometry and 24-h ABPM/ECG investigations. The mechanisms which lead to ST depression during stress in everyday life evidently differ from the conditions of ergometry with a slow incremental rise of exercise. Exercise which begins at $25 \mathrm{~W}$ or $50 \mathrm{~W}$ and is then raised gradually might be better tolerated due to the flow-mediated release of nitric oxide. 
Table 3 Hemodynamic parameters at the onset of ST depression with both methods (group D)

\begin{tabular}{|c|c|c|c|}
\hline $\begin{array}{l}\text { Values at I mV } \\
\text { ST depression }\end{array}$ & Ergometry & $\begin{array}{l}\text { 24-h ABPM/ } \\
\text { ECG }\end{array}$ & $\begin{array}{l}\text { Student's } \\
\text { t-test }\end{array}$ \\
\hline & Group D & Group D & \\
\hline $\begin{array}{l}\text { Systolic BP } \\
(\mathrm{mmHg})\end{array}$ & $188 \pm 35$ & $148 \pm 19$ & $\mathrm{P}<0.0001$ \\
\hline $\begin{array}{l}\text { Diastolic BP } \\
(\mathrm{mmHg})\end{array}$ & $86 \pm 16$ & $87 \pm 10$ & $\mathrm{P}=0.3664$ \\
\hline $\begin{array}{l}\text { Heart rate } \\
(1 / \mathrm{min})\end{array}$ & $|20 \pm 2|$ & $93 \pm 12$ & $\mathrm{P}<0.0001$ \\
\hline $\begin{array}{l}\text { Double product } \\
(\mathrm{mmHg} / \mathrm{min})\end{array}$ & $22992 \pm 3985$ & $137 \mid 4 \pm 2315$ & $\mathrm{P}<0.000 \mathrm{I}$ \\
\hline $\begin{array}{l}\text { Exercise } \\
\text { intensity (W) }\end{array}$ & $112 \pm 40$ & & \\
\hline
\end{tabular}

However, the present study design did not seek to discover the underlying pathophysiological reasons. Patients with coronary heart disease, but also hypertensives and patients with hypercholesterolemia often have a reduced coronary reserve (Vogt et al 1989) and are unable to react to acute physical exercise stress with adequate endothelium-mediated vasodilatation. In an investigation of hypertensives without clinical signs of coronary heart disease, $15 \%$ of patients showed depression of the ST-segment in the 24-h analysis or in the exercise ECG (Stramba-Badiale et al 1998). Notably, a proportion of the hypertensives with classic angina pectoris or ST depression had a normal coronary angiogram, ie, no macro angiopathy (Motz et al 1991; Uen et al 2000). However, these patients often showed scintigraphic signs of reversible myocardial ischemia, ie, they probably had micro angiopathy (Papanicolaou et al 1986; Cannon and Epstein 1988; Uen et al 2003). A rise in systolic and diastolic blood pressure as well as heart rate during Holter-detected ST

Table 4 Hemodynamic parameters at the onset of ST depression in ergometry (group B) versus ST depression in 24-h ABPM (group C)

\begin{tabular}{llll}
\hline $\begin{array}{l}\text { Values at I mV } \\
\text { ST depression }\end{array}$ & Ergometry & $\begin{array}{l}\text { 24-h ABPM/ } \\
\text { ECG }\end{array}$ & $\begin{array}{l}\text { Student's } \\
\text { t-test }\end{array}$ \\
\hline $\begin{array}{l}\text { Systolic BP } \\
\text { (mmHg) }\end{array}$ & $\begin{array}{l}\text { Group B } \\
189 \pm 23\end{array}$ & $\begin{array}{l}\text { Group C } \\
145 \pm 17\end{array}$ & $\mathrm{P}<0.000$ I \\
$\begin{array}{l}\text { Diastolic BP } \\
(\mathrm{mmHg})\end{array}$ & $96 \pm \mathrm{II}$ & $84 \pm \mathrm{I} 4$ & $\mathrm{P}=0.0086$ \\
$\begin{array}{l}\text { Heart rate } \\
(\mathrm{I} / \mathrm{min})\end{array}$ & $128 \pm 19$ & $96 \pm 21$ & $\mathrm{P}<0.000$ I \\
$\begin{array}{l}\text { Double product } \\
(\mathrm{mmHg} / \mathrm{min})\end{array}$ & $24083 \pm 4697$ & $13934 \pm 34 \mathrm{I4}$ & $\mathrm{P}<0.000$ I \\
$\begin{array}{l}\text { Exercise } \\
\text { intensity (W) }\end{array}$ & $134 \pm 39$ & & \\
\hline
\end{tabular}

depression has been described in earlier publications by the authors of the present study, as well as other working groups (Deedwania and Nelson 1990; Asmar et al 1996; Svenson et al 2001; Uen et al 2006). These results, and the findings reported in this study, show a substantially lower triggering threshold for the ST depression detected during 24-h ECG than the triggering threshold during ergometry. Thus it is likely that the ST depression in the 24-h ECG may possibly be explained by pathophysiological mechanisms different from those responsible for the ST depression detected in ergometry.

Patients who have normal ergometry but pathological ST-segment depression in the 24-h measurement are especially problematic. This was true for 23 patients in the present study (group B). Conversely, only 18 patients had a pathological ergometry and no ischemia during measurement in everyday life (group C). In the latter group, we could argue that the patients are not as highly exercise-stressed during everyday life as under full exercise in ergometry. However, in the first, larger group ergometry showed a false negative result despite its having reached the values for the double product which led to ischemia in everyday life. The extent to which the results of ergometry may possibly mislead physicians into making inadequate exercise recommendations for everyday life or for cardiac sport must be analyzed. However, Raby and colleagues (1993) observed ST depression in $21 \%$ of the $24-\mathrm{h}$ ECG investigations in 90 patients with normal symptom-limited ergometry. After an observation period of 719 days, detection of ST depression in the 24-h ECG investigation was the only independent predictor for sudden heart death, survived myocardial infarction, and development of unstable angina pectoris. Without 24-h ECG monitoring to detect ST-segment depression, the predictive value of ergometry for the prognostically important ST depression seems limited, especially in patients with nondiagnostic ergometry. It is also possible that Holter-detected ST depression may detect subgroups other than those identified by exercise testing and may thus have a different prognostic value.

Holter-detected ST depression is quite common in patients with stable or unstable coronary heart disease, and has about the same grave prognostic value as symptomatic ischemia. In recent studies the prognostic significance of ST depression in asymptomatic subjects, with no known coronary heart disease, could be demonstrated. A more than three-fold increase in the cardiac event rate was reported for middle-aged and elderly subjects with no apparent heart disease but with Holter-detected ST depression in a follow 
up of 5 years (Sajadieh et al 2005). Furthermore Stagmo and colleagues (2005) have recommended using Holterdetected ST depression as a complement to conventional risk factor evaluation, when deciding whether or not to treat risk factors for coronary heart disease in asymptomatic subjects, after they have the assessed 15-year risk of major coronary events predicted by Holter ST-monitoring in asymptomatic middle-aged men. Therefore we have not analyzed subgroups of patient with and without proven coronary heart disease in the present study. At all events, the prevalence of ST depression with poor prognosis is raised in hypertensives (Hedblad and Janzon 1992; Benetos et al 1998; Jong and Crijns 2001). Also our results indicate the unfavorable association of ST depression with uncontrolled hypertension. The percentage of patients with well controlled blood pressure (24-h ABPM $<130 / 80$ $\mathrm{mmHg}$ ) was lower in groups $\mathrm{C}$ and $\mathrm{D}$ compared with group A (Table 1). The differences in quality characteristics between the groups, as shown in Table 1, are based on a very small statistical power. Only a further study comprising a larger number of cases can clarify the extent to which these differences are valid.

\section{Limitations of the exercise test and Holter ECG}

The exercise test's ability to determine the localization and extent of ischemic myocardium is limited. Some ECGs cannot be interpreted because of abnormal baseline ST segments. Exercise-induced change in already abnormal ST segments is not well established, and has limited value in showing ischemia occurring in daily life.

One has to be careful not to label ST depression in Holter ECGs falsely as ischemia-related; ST shifts due to hyperventilation, position changes, or the Valsalva manoeuvre have been documented. Furthermore, some patients cannot be monitored when ST segments are permanently altered as a result of conduction disorders such as bundle branch block or myocardial infarction.

\section{Limitations of this study}

In this study, ST segment detection was performed with a twolead system in Holter ECG and with a 12-lead system in exercise ECG. Because of the retrospective character of the study, between bicycle exercise and 24 hour ambulatory monitoring, a maximum time elapse of three months was tolerated. The study did not analyze if and how the results were influenced by a possible change in patient condition between the two examinations, or by the different lead system.

\section{Conclusions}

In the present study, ST depression as detected by continuous ambulatory 24-h ABPM/ECG analysis under everyday conditions occurred more readily at low, double product levels than during standardized ergometry. In the detection of ST depression, ergometry and 24-h ECG do not replace, but complement each other. The results of the present work can support 24-h ABPM/ECG monitoring, in addition to exercise test, especially in patients with cardiovascular risk factors or previous cardiovascular events. Further investigations are required to clarify whether the group with ST depression under conditions of everyday life at low exercise show a poorer cardiovascular prognosis despite nonpathological ergometry with maximum exercise.

\section{Disclosure}

The authors report no conflicts of interest in this work.

\section{References}

Aronow WS, Ahn C, Mercando AD, et al. 2002. Prevalence of and association between silent myocardial ischemia and coronary events in older men and women with and without cardiovascular disease. J Am Geriatr Soc, 50:1075-8.

Asmar R, Benetos A, Pannier B, et al. 1996. Prevalence and circadian variation of ST-segment depression and its concomitant BP changes in asymptomatic systemic hypertension. Am J Cardiol, 77:384-90.

Banai S, Moriel M, Benhorin J, et al. 1990. Changes in myocardial ischemic threshold during daily activities. Am J Cardiol, 66:1403-6.

Barna I, Keszei A, Dunai A. 1998. Evaluation of Meditech ABPM-04 ambulatory BP measuring device according to the British Hypertension Society protocol. Blood Press Monit, 3:363-8.

Benetos A, Rudnichi A, Safar M, et al. 1998. Pulse pressure and cardiovascular mortality in normotensive and hypertensive subjects. Hypertension, 32:560-4.

Benhorin J, Banai S, Moriel M, et al. 1993a. Circadian variation in ischemic threshold and their relation to the occurrence of ischemic episodes. Circulation, 87:808-14.

Benhorin J, Pinsger G, Moriel M, et al. 1993b. Ischemic threshold during two exercise testing protocols and during ambulatory electrocardiographic monitoring. J Am Coll Cardiol, 22:671-7.

Benhorin J, Moriel M, Gavish A, et al. 1991. Usefulness of severity of myocardial ischemia on exercise testing in predicting the severity of myocardial ischemia during daily activity. Am J Cardiol, 68:176-80.

Cannon RO, Epstein SE. 1988. Microvascular angina as a cause of chest pain with angiographically normal coronary arteries. Am J Cardiol, 61:1338-43.

Deedwania PC, Nelson JR. 1990. Pathophysiology of silent myocardial ischemia during daily life. Hemodynamic evaluation by simultaneous electrocardiographic and blood pressure monitoring. Circulation, 82:1296-304.

Fleg JL, Gerstenblith G, Zonderman AB, et al. 1990. Prevalence and prognostic significance of exercise-induced silent myocardial ischemia detected by thallium scintigraphy and electrocardiography in asymptomatic volunteers. Circulation, 81:428-36.

Gaetano AL, Alessandro M, Vincenzo P, et al. 1997. Ischemic-like ST-segment changes during Holter monitoring in patients with angina pectoris and normal coronary arteries but negative exercise testing. Am J Cardiol, 79:1-6. 
Hedblad B, Janzon L. 1992. Hypertension and ST-segment-depression during ambulatory electrocardiographic recording results from the retrospective population study "Men born in 1914" From Malmö, Sweden. Hypertension, 20:32-7.

Jong B, Crijns HJ. 2001. Silent ST depression and cardiovascular endorgan damage in newly found, older hypertensives. Hypertension, 37:1083-8.

Motz W, Vogt M, Scheler S, et al. 1991. Coronary circulation in arterial hypertension. J Cardiovasc Pharm, 17(Suppl 2):35-9.

Papanicolaou MN, Califf RM, Hlatky MA, et al. 1986. Prognostic implications of angiographically normal and insignificantly narrowed coronary arteries. Am J Cardiol, 58:1181-7.

Pepine CJ, Sharaf B, Andrew TC, et al. 1997. Relation between clinical, angiographic and ischemic findings at baseline and ischemia related adverse outcomes at 1 year in the Asymptomatic Cardiac Ischemia Pilot study. ACIP Study Group. J Am Coll Cardiol, 29:1483-9.

Raby KE, Barry J, Treasure CB, et al. 1993. Usefulness of Holter monitoring for detecting myocardial ischemia in patients with nondiagnostic exercise treadmill test. Am J Cardiol, 72:889-93.

Sajadieh A, Nielsen OW, Rasmussen V, et al. 2005. Prevalence and prognostic significance of daily- life silent myocardial ischemia in middle- aged elderly subjects with no apparent heart disease. Eur Heart J, 26:1402-9.
Stagmo M, Juul-Möller S, Israelsson B. 2005. Fiteen-year risk of major coronary events predicted by Holter ST-monitoring in asymptomatic middle-aged men. Eur J Cardiovasc Prev Rehabil, 2:478-83.

Stramba-Badiale M, Bonazzi O, Casadei G, et al. 1998. Prevalence of episodes of ST-segment depression among mild to moderate hypertensive patients in northern Italy: the Cardioscreening study. J Hypertension, 16:681-8.

Svenson P, Niklasson U, Ostergren J. 2001. Episodes of ST-segment depression is related to changes in ambulatory blood pressure and heart rate in intermittent claudication. J Intern Med, 250:398-405.

Tzivoni D, Gavish J, Gottlieb S, et al. 1988. Prognostic significance of ischemic episodes in patients with previous myocardial infarction. Am J Cardiol, 62:661-4.

Uen S, Un I, Fimmers R, et al. 2006. Myocardial ischemia during everyday life in patients with arterial hypertension: prevalence, risk factors, triggering mechanism and circadian variability. Blood Press Monit, 11:173-82.

Uen S, Mengden T, Glänzer K, et al. 2000. Silent myocardial ischemia in hypertensive individuals. Praxis, 89:757-64.

Uen S, Baulmann J, Duesing R, et al. 2003. ST-segment depression in hypertensive patients is linked to elevations in blood pressure, pulse pressure and double product by $24 \mathrm{~h}$ 24-h ABPM/ECG monitoring. J Hypertens, 21:1-7.

Vogt M, Motz W, Strauer BE. 1989. Coronary flow reserve in arterial hypertension. Scand J Clin Lab Invest Suppl, 196:7-15. 